\title{
La Radio Comunitaria ¿Cómo resignificarla hoy?
}

Gretta Paiz Malespín ${ }^{1}$

\section{Resumen}

Las Radios Comunitarias surgieron en América Latina, como medios alternativos a la radio comercial y la radio estatal. Se posicionaron como una herramienta indispensable en el debate de temas emergentes desde la comunidad en un contexto marcado por principios de unidad, consenso, participación, discernimiento y diálogo.

No obstante, hoy esos contextos han cambiado, por lo que se hace inevitable abrir el debate y discutir las condiciones actuales de las Radios Comunitarias, bajo la premisa de re-significarlas desde nuevos escenarios desafiantes. Con este propósito surge el ensayo: “La Radio Comunitaria: ¿Cómo resignificarla hoy?”.

Esta es una propuesta que nace consciente del escenario complejo en que operan las Radios Comunitarias en América Latina, criminalizadas, marginadas e invisibilizadas por los Estados, los monopolios, los oligopolios y por los grupos de poder. A este panorama nada sencillo, se suma que también son radios divididas por geografía, edad, cultura, idioma, estilos de vida y formas de concebir el mundo.

Palabras clave: Radios Comunitarias; resignificación; audiencias; participación; América Latina.

\section{Summary}

The Community Radio's emerged in Latin America as alternative means to commercial radio and state radio. They were positioned as an indispensable tool in the debate of emerging issues from the community in a context marked by principles of unity, consensus, participation, discernment and dialogue.

However, today these contexts have changed, so it is inevitable to open the debate and discuss the current conditions of community radio stations, under the premise of redefining them from new challenging scenarios. With this purpose the essay appeared: "The Community Radio: How can we redefine it?"

This is a proposal that came out aware of the complex situation in which the community radio stations operates in Latin America, as they are criminalized, marginalized and invisibilized by States, monopolies, oligopolies and power groups. In

1 Directora del Instituto para la Comunicación Intercultural, ICI, de URACCAN. Estudiante PhD. en la Pontificia Universidad Católica de Chile. E-mail: grettapaiz@uraccan.edu.ni 
this panorama which is not so easy, we add the fact that they are radios that are also divided by geography, age, culture, language, lifestyles and ways of conceiving the world.

Keywords: Community Radio; Redefinition; Audience; Participation; Latin America.

\section{Introducción}

Este ensayo tiene el propósito de inducir a las Radios Comunitarias a re-significarse frente a audiencias reales en América Latina, desde la premisa que existe un nuevo contexto político, económico, social, cultural y tecnológico, y que sin duda alguna, están determinando los contenidos, la programación, los elementos que la caracterizan, sus objetivos, su misión, su visión, sus conceptos.

Se intenta identificar algunos puntos importantes de inflexión de las Radios Comunitarias, apoyado por la evidencia consignada en la revisión bibliográfica. En este aspecto, para llegar a la argumentación de puntos claves que guían este trabajo, se plantearon las siguientes preguntas: ¿Qué contextos y criterios llevaron a definir el concepto de Radios Comunitarias?, y ¿Qué elementos reconfiguran y resignifican hoy ese mismo concepto?

Vale resaltar que respecto a este ensayo, mi subjetividad como investigadora implicada con el tema desde la experiencia que por años me permitió a observar y vivir el proceso y la propia apuesta a las Radios Comunitarias, permea hoy inevitablemente mi análisis, consideraciones y conclusiones. Consigno que los referentes conceptuales relacionados a las Radios Comunitarias, provienen de la Asociación Mundial de Radios Comunitarias (AMARC), como la única fuente encontrada en esta revisión bibliográfica, para tales definiciones.

Dicho lo anterior, se discuten los orígenes de las Radios Comunitarias; presenta conceptos relacionados a las radios; reflexiona en torno a un contexto complejo para las Radios Comunitarias, situando como ejemplo algunos países de América Latina; características y atributos, consignando la experiencia del programa "Onda Local", de Nicaragua. Situa en el debate la re-significación, la comunidad y la gestión como conceptos significativos e importantes en el marco de una nueva mirada hacia, y desde las Radios Comunitarias.

Desde este breve análisis, se asume la re-significación, como la propuesta de discutir una nueva perspectiva de las Radios Comunitarias, como la capacidad de interpretar el pasado desde la situación que se vive en la actualidad (Molina-Valencia, 2013). El debate se propone cuando resulta indispensable avanzar en temas de inclusión, igualdad y equidad para que mujeres como Mireya Manquepillán, de Radio Kimche Mapú, 
de Lanco, Región de los Ríos en Chile, no tengan que llegar a la radio desafiando a los hombres y mujeres de su comunidad.

\section{Los orígenes de la Radio Comunitaria}

El origen de la Radio Comunitaria en América Latina tiene sus raíces en Radio Sutatenza, en Colombia, y las radios mineras en Bolivia (Ramos, 2007). Congruente con el tema convocado por este artículo, la Organización de las Naciones Unidas para la Educación, la Ciencia y la Cultura (UNESCO), presenta la primer perspectiva significativa de las Radios Comunitarias: "surgieron como un medio que dio voz a los sin voz". Por consiguiente, se confirma que "la radio continua siendo el medio de comunicación más universal”, y "con mayor presencia" en la mayoría de los países latinoamericanos.

Las primeras Radios Comunitarias empezaron a nacer en América Latina a mediados de los años 8o, en un escenario de vientos democráticos, desafíos de dictaduras, gobiernos totalitarios y represivos en América Latina y en el mundo (Tufte, 2011). Contradictoriamente no existen datos confiables que confirmen cuántas Radios Comunitarias existen hoy. Desde su surgimiento, han sido asociadas a grupos de comunidades que acceden a ella, para expresarse, organizarse, discutir y alcanzar el consenso; articularse, proponer y defender sus propios proyectos e iniciativas, y darle voz a sectores históricamente marginados. Su importancia resulta mucho más significativa en territorios donde es la única fuente de información para las comunidades (Rodríguez, 2014).

\section{El concepto de la Radio Comunitaria}

La Asociación Mundial de Radios Comunitarias, define el concepto de Radios Comunitarias a partir de la pregunta: ¿Qué hace que una estación de radio sea comunitaria?, con la que responde: "es una Radio Comunitaria, rural cooperativa, participativa, libre, alternativa, popular, educativa. musical, militante, musicales y militantes. En áreas rurales, como en el corazón de las ciudades más grandes del mundo".

De acuerdo a estas categorías, se entiende por Radios Comunitarias todas, incluyendo las radios religiosas, menos las comerciales y las del Estado, estas últimas, reconocidas como las oficialistas. Geerts y Van (2001), despejan y esclarecen sobre la base de la comprensión que cada clasificación representa su propia razón de ser. Con este hallazgo, en una de las referencias bibliográficas más antiguas sobre las Radios Comunitarias, se hace necesario discutir y clarificar más sobre qué se entiende finalmente como Radios Comunitarias hoy, desde el carácter que por sí mismo incorpora el concepto de radio, definido por González (2015), como un medio de comunicación masivo que se rige por la aceptación, rechazo o adaptación encaminada hacia la diversidad o usos sociales, reconociendo en estos últimos, los que han marcado el desarrollo y el rumbo de la radio desde sus orígenes. 
Pero, ¿cuáles son estas Radios Comunitarias? ¿Son comunitarias porque están circunscritas a un territorio y a un pueblo determinado? ¿Será que el término de comunitariedad de la radio, obedece a los procesos de participación e involucramiento de los distintos sectores poblacionales? La gran pregunta a saber, es a quién pertenecen hoy estas radios, inicialmente surgidas a la luz de intereses comunitarios y sin fines de lucro, de organizaciones, cooperativas, estudiantes, universidades, municipalidades, iglesias y sindicatos.

En relación a las radios de iglesias, hay quienes consideran que las radios religiosas hacen "proselitismo". Al menos, proselitismo religioso, que por lo visto molesta a las asociaciones consignadas por Chaira Sáez (2014) en su libro sobre TV comunitaria, las cuales no consideran "proselitismo" el promover la ecología, los derechos humanos y ciertas posturas políticas que hacen, en este caso, algunas televisoras comunitarias. En razón de este planteamiento, se hace necesario transparentar ¿bajo qué criterios, la Radio Comunitaria sí representa ese fenómeno cultural, social y ciudadano? (Pincheira M, L. E., 2013).

Distintos autores han llegado a la conclusión que las Radios Comunitarias trascienden a la comunidad, grupos barriales, campesinos, y otras organizaciones de la sociedad que tienen el derecho a asociarse para gestionarla de forma democrática y auto-sostenible (Flores, 2006), sobre la base de la independencia política, económica e ideológica (...)". El punto de partida, que los autores consignan como válido en este debate por la resignificación, es la independencia. De acuerdo a esta postura, las radios, son comunitarias cuando son capaces de ser independientes, política, ideológica y económicamente. Cuando son consistentes con criterios de rentabilidad social y financiera, que las llevan a operar asegurando indicadores como la promoción de la diversidad, el pluralismo y la interculturalidad (Sáez, 2014).

\section{El dedo en la llaga}

Siguiendo a López Vigil, una radio es comunitaria cuando se promueven estos criterios:

Cuando la radio fomente la participación de los ciudadanos y defiende sus intereses; cuando refleja los gustos de la mayoría y hace buen humor y la esperanza es su objetivo principal; cuando verdaderamente informa; cuando ayuda a resolver los mil y un problema de la vida diaria; cuando todas las ideas son debatidas en sus programas y todas las opiniones son respetadas; cuando la diversidad cultural es estimulada por encima de la homogeneidad comercial; cuando las mujeres son las actoras principales en la comunicación y no simplemente una voz bonita o un artilugio para la publicidad; cuando ningún tipo de dictadura es tolerada, ni siquiera la dictadura musical de los grandes estudios de grabaciones; cuando las palabras de todos vuelan sin discriminación o censura. 


\section{CIENCIAS SOCIALES}

Al parecer, López Vigíl ha puesto 'el dedo en la llaga' con relación a la significancia de las Radios Comunitarias. En su momento, radialistas en Chile durante el Seminario Internacional: "Comunicación Comunitaria para el Nuevo Siglo", realizado en Santiago, en mayo del 2015, discutían y proponían esa mirada distinta, la misma con la que intento la re-conceptualización de Radios Comunitarias definiendo como criterios válidos y significativos los siguientes: la participación de la comunidad en el proyecto de Radio Comunitaria; la defensa de los intereses de las personas, sin distingos políticos, religiosos y culturales, la promoción de la paz, la solidaridad y colaboración como principios importantes para vivir en comunidad, el respeto a todas las ideas, promover e incentivar a los Estados asumir la diversidad cultural de un país, la inclusión de mujeres como actoras principales en el ejercicio radial, la no dependencia política, económica e ideológica, y la no discriminación ni censura.

En consecuencia, la Radio Comunitaria debe estar 'más allá del bien y del mal'. Mientras esto no pase, se debería de asumir que se trata de una "radioemisora" que se ha alejado de su proyecto de vida, que es la gente, la comunidad, la audiencia, y por tanto, ya no reúne las condiciones que un día la llevó a llamarse: Radio Comunitaria.

\section{La contribución de las Radios Comunitarias}

La Open Society Foundations, en el contexto del proyecto: Trazando el Mapa de los Medios Digitales, examina con abundante información la influencia que las nuevas tecnologías está imponiendo al periodismo, los medios de comunicación, y por consiguiente a las Radios Comunitarias (Ávila y Gutiérrez, 2013; Zuluaga y Martínez, 2012; Zúniga y Hopmann, 2013; Becerra, Merino y Mastrini, 2012; Gómez y Soza-Plata, 2011; Godoy y Groenemeyer, 2012).

El informe da cuenta qué son los medios comunitarios, especialmente la Radio Comunitaria, los que ofrecen la mejor oportunidad de desafiar la narrativa dominante de las empresas de medios de comunicación, en un ambiente en el que corresponde a las organizaciones comunitarias y religiosas desplegar activos esfuerzos en la producción de contenidos (Ávila y Gutierrez, 2013).

La perspectiva presentada por Ávila y Gutiérrez, consigna la existencia en América Latina de las radios religiosas. El punto de vista de Pincheira (2013), permite comprender en el caso particular de Chile, que la Radio Comunitaria apareció bajo el alero de la iniciativa de la iglesia Católica. De acuerdo, a Sergio Godoy (2015), especialista en el tema y con amplia trayectoria en la investigación de medios digitales, televisivos y radiales, esto se debe a que la iglesia Católica fue pionera en radios educativas y de bien común en Latinoamérica, ante la ausencia del Estado y el comercialismo de las radios privadas. 
Al respecto, Patricia Orozco, en la página de AMARC, Nicaragua (2015), reivindica la contribución de la Radio Comunitaria como el principal medio de comunicación que la gente utiliza. Efectivamente la radio en Nicaragua es el medio de comunicación dominante, utilizado por más del 8o por ciento de la población (Gutiérrez y Hopman, 2013). Popularidad con la que coincide Rodríguez (2014), al dejar consignado que Chile es un país donde la radio es un medio de alta audiencia y muy valorado por la población.

Pese a ello, el uso extendido de la radio no implica que las Radios Comunitarias tengan impacto relevante, en comparación a la propia televisión o las redes sociales que han conseguido cautivar a un amplio sector de la población, que muchas veces prefiere recurrir a la Internet. Esto tiene que ver con la programación y los contenidos mismos, que pueden estar o no, motivando a la audiencia de los distintos pueblos en América Latina.

\section{Los cambios registrados en la actualidad}

Paradójicamente al apagón de la radio análoga principalmente en Europa, la Internet ha irrumpido con gran fuerza transformadora, marcando la transición de la sociedad industrial a la sociedad digital (Franco, 2009). El informe refiere que en lugares en los que la penetración de Internet es baja, o no se alcanza, la radio se alza como una gran alternativa.

En los casos de América Latina, como países en vías de desarrollo, las Radios Comunitarias constituyen hoy por hoy el medio por excelencia de recibir información. No obstante, el avance de las nuevas Tecnologías de la Información y la Comunicación (TICs), representa una realidad desafiante para las propias Radios Comunitarias obligadas en este contexto a ir por nuevos emprendimientos.

El cambio importante de la radio analógica a la radio digital (Álvarez, 2008), también trae consigo ventajas y desventajas que deben analizarse de tal forma que permitan trascender a sus verdaderas implicancias. En este sentido, Chiara Sáez (2014), consigna la digitalización más allá de un cambio tecnológico, asegurando que en materia de digitalización los medios no lucrativos o comunitarios son los que con más dificultades acceden a la transición digital, y no por ello deber ser excluidos del proceso, dado el rol social que cumplen:

Estos: “(...) se erigen como medios que canalizan la expresión donde los integrantes del sector pobre suelen tener mayores oportunidades de acceso y participación en relación a las posibilidades que pudieran tener en los medios tradicionales (...) responden en muchos casos a las necesidades, intereses, problemas y expectativas de sectores muchas veces relegados, discriminados y empobrecidos de la sociedad civil. La necesidad creciente de expresión de las mayorías y minorías sin acceso a medios 
de comunicación, y su reivindicación del derecho de comunicación, de libre expresión de ideas, de difusión de información" (RELE -CIDH, 2002: Cap. VI).

Con este escenario, interesa discutir si una Radio Comunitaria por Internet sigue manteniendo su condición de Radio Comunitaria. ¿Es Radio Comunitarias una iniciativa de emitir audios por Internet, con un esquema de funcionamiento de carácter colectivo, ciudadano, incluso si no usa espectro electromagnético -que es de libre acceso? A mi criterio, estas son interrogantes que deben ser respondidas por los usuarios, llámense audiencias, comunidades, o pueblos, mediante el uso del principio del consentimiento, previo, libre e informado.

\section{Características y atributos de las Radios Comunitarias}

En esta parte del análisis se consignan características y atributos, que deberían hacer de una estación, una Radio Comunitaria. Sin embargo, no significa que sean estos mismos criterios los que estén presentes en cada una de las Radios Comunitarias hoy. Según AMARC, las Radios Comunitarias "se caracterizan por atributos y finalidades que se relacionan directamente con las de la comunidad a la cual sirven y representan", siendo éstas las siguientes: (i) una actividad con fines no lucrativos (no se someten a la lógica del dinero ni de la propaganda); (ii) Trata de influir en la opinión pública, de crear consenso, de ampliar la democracia y construir comunidad; (iii) Promueve la participación de los ciudadanos y defiende sus intereses; (iv) Se involucra en la vida cotidiana y contribuye a resolver los problemas emergentes; (iv), Cuando en sus programas se debaten todas las ideas y se respetan todas las opiniones.

Relacionado con lo anterior, el estudio "Radios Comunitarias y contexto de conflicto en México" (AMARC 2008), asegura que: "las Radios Comunitarias no tienen un discurso neutro", al contrario, "en su lenguaje en sus emisiones se plasma su postura política, comunicativa y ética, la cual puede llevar bien a reducir, atizar o aportar en la resolución de un conflicto". Por consiguiente, esta posición contradice lo que ha declarado AMARC cuando en el párrafo anterior afirma que en las Radios Comunitarias "se debaten todas las ideas y se respetan todas las opiniones".

Claramente existen ideas y opiniones que son atacadas, criticadas y rechazadas. Quizás justificadamente, quizás no. Lo cierto es que este aspecto introduce en la discusión la noción de "comunidad” homogénea y participativa que, y cuidado, puede ser incluso falsa o equivocada en muchos casos. Incluso en poblados rurales pequeños. La realidad que hoy viven las Radios Comunitarias está permeada por un contexto de las sociedades contemporáneas de fragmentación, polarización y dificultades para mantener la cohesión.

Esta reflexión recoge la complejidad con la que se recrea la ecología de las Radios Comunitarias hoy, sus líneas editoriales, programas, contenidos, relaciones, y pone 
en el centro de la discusión a las comunidades de audiencias, en el entendido que la radio pertenece a una comunidad, que está circunscrita a un territorio que vive su propia dinámica, con acuerdos y desacuerdos. Una comunidad donde convergen otras radios y otros medios de comunicación.

Una característica de las Radios Comunitarias es que se basa en la comunicación y el diálogo como construcciones sociales de acción en la comunidad (Baca, 2013), pero contradictoriamente, al recorrer desde este ensayo la experiencia del programa "Onda Local", en Nicaragua, estos atributos no son consistentes con la libertad de expresión que necesitan las radios para dialogar horizontalmente con su audiencia, crear consenso y por ende ampliar la democracia.

"Onda Local", es un programa de Radio Comunitaria, "que consiste en entrevistas, reportajes y debates sobre temas de desarrollo municipal y local, y derechos de género" (Gutiérrez y Hopman), ampliamente reconocido y aceptado en Nicaragua, conducido por la periodista Patricia Orozco, y que consigna públicamente su oposición al actuar del Gobierno de Daniel Ortega, en restringir las libertades de expresión, obligado a pedir públicamente a la audiencia "apoyo económico solidario", para no cerrar. Autores como Ávila y Gutiérrez (2013), reconocen como lo más grave que se produce en experiencias como la recientemente discutida, la interferencia estatal en los medios de comunicación incrementada mediante nuevas tácticas indirectas para suprimir la información y la disidencia.

\section{La comunidad en la gestión integral}

Una radio se hace comunitaria cuando se entrega a la comunidad, cuando atiende sus gustos y necesidades (Geerts y Van, 2001). Se trata de promover una gestión integral basada en una comunidad significativamente importante para definir de forma concertada, los contenidos y la producción. Villamayor y Lamas (2008), definen la gestión en la Radio Comunitaria, como el proceso de construcción colectiva desde las identidades, las experiencias y habilidades de quienes allí participan. Paradójicamente, el contexto que hoy se vive en la comunidad, se distancia del ideal de colectivo con intereses comunes (AMARC, 1998), imperando relaciones de convivencia complejas (FAO), poniendo a grandes pruebas a las radios, en una de sus misiones en promover el desarrollo de las comunidades (Álvarez, 2008).

Más importante aún, una Radio Comunitaria requiere también de un cambio frente a su propia audiencia. Al respecto, Valerio Fuenzálida (2015), referente importante en estudios de audiencia en América Latina, sostiene que la audiencia valora los atributos de independencia y profesionalismo. Esto implica por tanto, que en este proceso de re-significar a las Radios Comunitarias es importante potenciar iniciativas que re-direccionen acciones de co-dependencia por independencia. 
Parafraseando a Fuenzálida (2011), las expectativas de las audiencias en Latinoamérica, en relación a la acción política de los medios de comunicación, la Radio Comunitaria debe abandonar la tradicional función propagandística a favor de dictadores, caudillos y gobernantes de turno; en cambio debe asumir la función de comunicar a favor de las audiencias (...), contribuyendo a la mejoría de la calidad de la política regional, cuya actividad implica una asignación imperativa de valores para una sociedad. Evidentemente, se trata de un término que no sólo configura el poder, sino al contrario, invoca a valores, principios y horizontes sociales por parte de los distintos grupos y actores que luchan por imponer su cosmovisión del mundo o la realidad (Schneider y Avenburg, 2015).

Con la crítica irrebatible de Fuenzálida las Radios Comunitarias en América Latina están en dificultad, y tienen que hacerse cargo críticamente de sus propias carencias y deficiencias. Re-signicar las Radios Comunitarias es pensarlas como el proyecto que acercó los micrófonos a una comunidad significativamente importante para que el proyecto de las Radios Comunitarias fuese una realidad. La re-significación de las Radios Comunitarias hoy, debe traducirse a un divorcio, el más radicalizado, con los grupos de poder.

\section{El contexto actual de las Radios Comunitarias}

La UNESCO (2014), es contundente al describir el contexto caracterizado en la región por la elevada polarización entre los grupos mediáticos favorables y opositores al gobierno. América Latina, es una región compleja, con realidades disímiles derivadas de los distintos caminos atravesados durante los procesos de consolidación política, cuya consecución sufrió constantes rupturas causadas por dictaduras cívico-militares apoyadas por grupos de poder nacionales y extranjeros (FIP: 2015).

\section{Concesiones y asignación de las licencias}

$\mathrm{Al}$ análisis anterior se suma el tema del espectro radioeléctrico que es administrado por el Estado en Latinoamérica casi como si fuese un bien privado, olvidando su responsabilidad precisa en "el control de la planificación, gestión, uso y vigilancia del espectro" (Álvarez, 2008). Por esta razón, se requiere un régimen jurídico especial relacionado con la satisfacción del interés público o interés general (Sáez, 2014), transparentando la asignación de las licencias y el espectro bajo criterios y objetivos claros, públicos y democráticos (CIMA, 2014).

\section{La concentración y los oligopolios de los medios}

América Latina es uno de los continentes que presenta los mayores índices de concentración de medios y oligopolios mediáticos comerciales en una estrecha vinculación (e incluso a veces una estrecha identidad) con las élites gobernantes, generándose 
una peligrosa relación entre los dueños de los medios de comunicación y los dueños del poder político (AMARC, 2009).

Otras dimensiones de la concentración de medios son el acaparamiento de la propiedad en un número limitado de individuos o empresas (monopolio u oligopolio) y la dominación del mercado por parte de éstas. Algunos casos documentados de concentración en Latinoamérica son de Televisa en México y Globo en Brasil.

En el caso costarricense, los medios de comunicación están en pocas manos y una sola agenda, situación similar vivida en restos de los países del área, como Guatemala, Nicaragua, El Salvador y Honduras. En todo caso, se trata de una concentración que mantiene restringido el espacio público, la pluralidad de opiniones, las libertades y la democracia (Pinto, 2012).

\section{Otros aspectos de la discusión}

En un continente tan desigual como América Latina (Condeza y de Fontcuberta, 2014), las Radios Comunitarias deberían asumir el desafío de sentarse a discutir en un ejercicio impostergable que las lleve a reconsiderar aspectos vitales ligados a cambios considerables y que han mermado la capacidad de asumirse como la radio que un día llegó y se quedó en la comunidad, en la universidad, en el campo y la ciudad, en aras de "fortalecerse y crecer" (Gerbaldo, 2013).

La escasa bibliografía actualizada sobre las Radios Comunitarias, evidencia la necesidad de definir mecanismos que permitan agendar desde AMARC, ALER, FELAFACS, escuelas y facultades de comunicación, procesos que propicien estudios sobre la realidad hoy de las Radios Comunitarias, en una discusión que emerja desde actores claves de la comunidad para recuperar la historia y re-establecer una nueva mirada en contextos complejos y desafiantes.

El proceso de revisión bibliográfica que guió este artículo, evidencia argumentos contradictorios y pocos claros respecto a: el modelo de financiamiento de las Radios Comunitarias; decisión frente a los contenidos de las radios; la propiedad de las radios; las licencias otorgadas; en que circunstancias prima la libertad de expresión; y quiénes hacen hoy Radio Comunitaria.

\section{A manera de conclusiones}

Por todo lo discutido en este ensayo, la principal conclusión que quiero consignar es que hoy las Radios Comunitarias no siguen siendo un concepto válido, fundamentado en un contexto complejo que ha llevado a unas, a atrincherarse en un discurso frontal y de resistencia contra un sistema que las marginaliza y las criminaliza; a otras, a sumarse como activistas y abanderadas de proyectos políticos que paradójicamente, 


\section{CIENCIAS SOCIALES}

no han contribuido a la cohesión de la población, y muy al contrario, se consigna el fraccionamiento de una comunidad que ya vivía sus propias complejidades.

Mi experiencia con el tema, me lleva a considerar, que efectivamente las Radios Comunitarias han dejado de tener esa misma significancia, y por tanto, hay que resignificarlas, desde un ejercicio de regresión que lleve a las Radios Comunitarias al punto de partida, de valorar a una audiencia propositiva, crítica, con puntos de convergencia y desacuerdos, crecida, diversa, con cosmovisiones e identidades particulares, con contradiciones y culturas diferentes, rezándole al Dios de su preferencia, solidario, conflictivo, pasivo, activo, pobre, rico. Resignificar las Radios Comunitarias hoy, es pasar de la palabra a la acción y dejar de seguir viendo a una audiencia que no tenía voz.

Por tanto, la primer tarea que propongo es abrir un debate público, incluyente, participativo de todos los actores/as, sectores, comunidades, municipios, comarcas, ciudades, de todas las experiencias en radio, educativa, universitaria, Católica, evangélica, municipal, política, gremial, organizativa, institucional, y solamente después, volver a re-conceptualizar a las Radios Comunitarias. Se trata por consiguiente de una iniciativa donde sus verdaderos protagonistas son las propias Radios Comunitarias.

De allí que se entienda que la propuesta, es re-significar las experiencias pasadas y presentes, que lleven a la articulación de los medios de comunicación en el tema radial, generar alianzas entre las radios, y profundizar la discusión en el seno de las comunidades, comarcas, municipios, ciudades, a fin de alcanzar el desafío propuesto de re-significar las Radios Comunitarias en su esencia, en su vitalidad, en sus conceptos $\mathrm{y}$ en los conceptos que la gente tiene de ellas.

Este proceso propuesto a mi consideración debe partir haciéndose las siguientes preguntas: ¿Sigue siendo la Radio Comunitaria valorada como el medio y el espacio que una vez abrió sus micrófonos, los compartió con la comunidad y los dejó al resguardo de esta? ¿En manos de quién están hoy las Radios Comunitarias? ¿Quién decide las políticas de la radio?, y, ¿Quién define su programación?

El debate sugerido debe llevar a las Radios Comunitarias grandes y pequeñas a re-significarse a la luz de nuevos contextos tecnológicos, económicos, sociales, políticos y culturales.

\section{Lista de referencias}

Ávila y Gutiérrez. (2013). Los Medios Digitales: Guatemala. Open Society Foundations.

AMARC (2010). ¿Qué es AMARC?. 
AMARC (2009). Las mordazas invisibles. Nuevas y viejas barreras a la diversidad en la radiodifusión.

Álvarez Moreno (2008). El desafío de las Radios Comunitarias. p. 61-77.

AMARC (2008). Radios Comunitarias y contexto de conflicto en México.

AMARC (Sin Fecha). ¿Qué es una Radio Comunitaria?

Baca F. (2013). El papel de la Radio Comunitaria en el panorama mediático mexicano del siglo XXI. Los casos de Radio Teocelo, Radio Huayacocotla, Radio Plantón y Estéreo Comunal.

Becerra, Merino y Mastrini (2012). Los Medios Digitales: Argentina. Open Society Foundations.

Benítez, J. (2011). Medios de Comunicación Comunitarios y retos para los comunicadores en el Siglo XXI.

Banerjee, I. y Seneviratne, K. (2005). Radiotelevisión de Servicio Público: Un manual de Mejores Prácticas. UNESCO. (1), 1-140.

Condeza y Fontcuberta Mar de (2014). Comunicación y educación. Ampliando Las Fronteras. Cuadernos Info, 35, 219-231.

Courtney, Radsch y Pollack. (2014). Tendencias mundiales en libertad de expresión y desarrollo de los medios: Situación Regional en América Latina y El Caribe. UNESCO.

CIMA (2012). Potenciando a los medios independientes. Center for International Media Assistance (CIMA) and National Endowment for Democracy (NED), por sus siglas en inglés.

Colin y Restrepo (2001). Community radio handbook. UNESCO.

FIP (2015). Informe sobre amenazas a la libertad de prensa en Latinoamérica y el Caribe. Federación Internacional de Periodistas. p. 1-12.

Fuenzálida, V. (2015). Televisión Pública y Cambio Digital. Tecnología TV - Audiencias - Formatos. Punto Cero. Universidad Católica Boliviana, 20(30) 46-31.

Fuenzálida, V.(2011). Resignificar la educación televisiva: desde la escuela a la vida cotidiana. Comunicar, XVIII(36) 15-24. 


\section{CIENCIAS SOCIALES}

Franco, G. (2009). El impacto de las tecnologías digitales en el periodismo y la democracia en América Latina y el Caribe.

Flores, C. (2006). La influencia de las Radios Comunitarias: Caso Radio Ayabaca.

FAO (Sin Fecha). Comunidad.

González, L, F. (2015). La radio y la tecnología. Revista Mexicana de Ciencias Agrícolas,(12)205-207.

Gerbaldo, J. (2013). Tensiones y Desafíos emergentes para las Radios Comunitarias en la implementación de la Ley SCA.

Godoy y Gronemeyer (2012). Los Medios Digitales: Chile. Open Society Foundations.

Gómez y Sosa-Plata (2011). Los Medios Digitales: México. Open Society Foundations.

García, G. (2010). Manual para radialistas Analfatécticos.

Geerts y Van (2001). La Radio Popular frente al nuevo siglo: estudio de vigencia e incidencia. ALER.

Lee, P. (2012). Día Mundial de la Radio 2012: tiempo de celebración. World Association for Christian Communication (WACC Caribe).

López, V. (2008). Ciudadana Radio. El poder del periodismo de intermediación.

López, V. (2005). Manual Urgente para Radialistas Apasionados.

Lumko et al (1998). What is Community Radio? A Resource Guide. AMARC Africa.

Molina, V. (2013). Discusiones acerca de la Resignificación y conceptos asociados, p. 39-63.

Mercado, Castro y Coria (2012). La Radio para la Pluralidad de Voces.

Rodríguez, R (2014). El radioteatro como herramienta educativa para promover el patrimonio inmaterial: hombres y mujeres del mar en el sur de Chile. Cuadernos. Info, 35, 29-38.

Ramos, V. M. (2007). La Radio Comunitaria frente a los grupos de poder. Razón y Palabra, 12 (59).

RAE (Sin Fecha). Resignificar. Real Academia Española. 
Schneider y Avenburg. (2015). Cultura Politica: Un concepto atravesado por dos enfoques. Revista POSTData: Revista de Reflexión y Análisis Político, 20(1), 109-131.

Sáez, B, Ch. (2014). TV Digital en Chile. Políticas Públicas y Democracia. Universidad de Chile. Instituto de la Comunicación e Imagen. Editorial Universitaria Estudios.

Pincheira M. (2013). Radio comunitaria, un espacio educativo no formal en la comunidad. REXE. Revista de Estudios y Experiencias en Educación, 12(24), 183-193.

Quintero, W. (2014). Encuentro Centroamericano de defensores y defensoras de Derechos Humanos.

Pinto, L. (2012). Malos tiempos para la Comunicación en Centroamérica.

Tufte, T. (2011). ¿Dónde están los medios públicos en América Latina? Medios ciudadanos $y$ transformación nacional en un contexto "glocalizado".

UNESCO (2012). UNESCO y el Programa Internacional para el Desarrollo de la Comunicación.

Vásquez, G, S. (2014). Radios Comunitarias e Indígenas, legítimas pero "ilegales”.

Villamayor y Lamas (2008): La Gestión de la Radio Comunitaria y ciudadana.

WAN-IFRA (2014). Comprando Complacencia: Publicidad Oficial y censura indirecta en México. Asociación de Periódicos y Editores de Noticas (WAN-IFRA, por sus siglas en inglés).

Zúniga y Hopmann (2013). Los Medios Digitales: Nicaragua. Open Society Foundations. Zuluaga y Martínez (2012). Los Medios Digitales: Colombia. Open Society Foundations. 